\title{
Repeated maternal separation in the monkey '
}

\author{
G. D. MITCHELL, H. F. HARLOW, G. A. GRIFFIN AND G. W. MфLLER \\ PRIMATE LABORATORY, UNIVERSITY OF WISCONSIN
}

Repeated early maternal separations increase the levels of coo vocalizations and fear. This syndrome persists when the Ss are tested one year after the final maternal separation.

The short-term separation syndrome of increased coo vocalizations and depression in the infant monkey has been replicated several times (Seay, Hansen, \& Harlow, 1962; Seay \& Harlow, 1965; Kaufman \& Rosenblum, 1967). The present paper reports separation effects one year after eight infant monkeys had experienced repeated maternal separations throughout the first eight months of their lives.

Subjects

The three sex-balanced groups of four Ss used in the present study were Macaca mulatta, and were former members of a repeated separation study at the Wisconsin Primate Laboratory (Griffin, 1966). A sex-balanced group of four Ss was reared by four different mothers (Group RM-Rotated Mothers). They were repetitively separated from one mother for $2 \mathrm{~h}$ every two weeks and then returned to one of three others. Another four Ss were separated but returned to the same mother after each separation (Group RS). The last four Ss (Group NC) were never separated. All Ss were deprived of peer interaction, hence peer experience could not be confounded with the separation conditions during the first eight months of life. Tests for long-term RM and RS effects were conducted when the Ss were 19 months old, nearly one year following the initial treatments. Following the Griffin (1966) project the Ss were housed in two groups of six which were balanced for both sex and rearing.

Two stimulus animals were used, one adult (age 5-1/2 years) and one infant (age one month). The adult, a female, was an extremely aggressive total social isolate and was selected to educe fear. The infant, a male, was chosen to elicit a minimum of fear or, potentially, aggression.

\section{Apparafus}

For the first eight months of life each $\mathrm{S}$ was housed with a mother in a playpen described by Hansen (1966). They could see and interact only with their own mother.

At 19 months of age each $S$ was paired with each stimulus animal in a $6 \mathrm{ft} \times 2 \mathrm{ft} \times 3 \mathrm{ft}$ high cage. There was a door (16 $\times 9$ in.) at one end through which the $\mathrm{Ss}$ entered. Frequencies were recorded for five behaviors by a counter system operated manually by an $\mathrm{E}$.

\section{Procedures}

The Ss were adapted to the test cage for $2 \mathrm{~h}$ in their home-cage groups. The stimulus animals were adapted individually for $2 \mathrm{~h}$. Each $\mathrm{S}$ was first paired four times with the infant. The order of testing for these 48 infant sessions was balanced across age, sex, rearing, and E. After the adult had been adapted, the 12 Ss were then paired four times with her. The stimulus animal remained in the test cage while the $S$ was changed. Each $S$ was tested once a day between 9 AM and 3:30 PM and twice a week. Testing began when the $S$ entered the cage and terminated after $5 \mathrm{~min}$.

Each of two Es tested six Ss which were matched across Es for age, sex, and rearing. The $\mathrm{E}$ effect was included in an analysis of variance on each of the five behaviors and an alpha level of .05 was employed.

Resulis

The Es were significantly different in the scoring of one category-fear grimace. No group blas resulted from this difference, but the statistical precision or efficiency for fear grimace is probably inferior to those of the other four categories.

All numbers appearing in parentheses below are mean frequencies per group across both stimulus animals, i.e., they are significant main effects. Group RS monkeys were more disturbed in the test cage than were the NC Ss. The RSs (58.5) screeched significantly more often than the NCs (7.0) and were the only Ss who screeched in the presence of the infant. The frequencies of fear grimace (87.3 vg 45.0) and social submission (1.3 vs 0.0$)$ were significantly elevated in the RSs and, while the NCs frequently threatened the stimulus animals, the RSs never threatened. The RSs (379.0) emitted nearly seven times as many coos as the $\mathrm{NCs}(59.0)$, and there was no overlap between the two groups.

The RMs (14.3) screeched more frequently than the NCs (7.0) but not as often as the RSs (58.5). The fear grimaces (36.0) and social submissions (0.0) shown by the RMs were at the NC level. Social threats, on the other hand, were significantly higher in the RMs (4.5) than in the NCs (1.8). The RM males were the only Ss who threatened the adult female.

Discussion

The overall results indicate that the mother-infant affectional tie is of major importance in monkey development. It was the impression of both Es that the peer deprived monkeys were surprisingly normal. This does not in any way detract from the importance of infant-infant affection. The results emphasize the mother's capability of compensating for the absence of peers, but infant-infant interaction can also compensate for the absence of a mother (Harlow \& Harlow, 
1962). Because Group NC was quite normal and because peers can compensate for maternal absence, it follows that the mother-only situation is a cleaner design for imposing differential maternal treatments than more natural social settings.

Single traumatic maternal separations produce predictable overprotection responses in the mother upon return and increase coo vocalizations and social submission in the infant during maternal absence (Seay, Harlow, \& Hansen, 1962). It is this same infant reaction to separation which persists for a year following the final maternal separation, hence the specific symptoms of acute mother-infant separation can become chronic aberrations if separation is repeated throughout infancy.

The coo vocalization is a sensitive index of separation and has been repeatedly defined as a call by the infant for social or physical contact (Rowell \& Hinde, 1962). Van Hooff (1962) stated that the coo belongs to the mother-child relation and expresses the need for body comfort. He noted that the coo stopped when the infant was cuddled in response to it. Thus, the coos are quite specific indicants of maternal separation.

Human children who experience separation are sald to be sensitized so that later similar experiences are traumatic for them (Yarrow, 1964). It appears that the monkey Ss here have also been sensitized. Repeated social conditioning of the acute separation reaction and particularly of the coo apparently occurred. The return of the infants to their mothers after each separation was a strong social relnforcement for cooing and the coo vocalization during matermal absence appeared most consistently in those returned to their own mother. Whatever the mechanism, pre- vious separations do not reduce but rather increase the disturbing effects of subsequent separations. The infant never adjusts to being separated and an exaggerated separation response persists a full year after the final maternal separation. Yarrow's (1964) notion of a sensitization to separation is strongly supported.

\section{References}

Griffin, G. A. The effects of multiple mothering on the infant-mother and infant-infant affectional systems. Unpublished doctoral dissertation, University of Wisconsin, 1966.

Hansen, E. W. The development of maternal and infant behavior in the rhesus monkey. Behaviour, 1966, 27, 107-149.

Harlow, H. F., \& Harlow, M. K. Social deprivation in monkeys. Scient. American, 1962, 205, 2-10.

Kaufman, I. C., \& Rosenblum, L. A. Depression in infant monkeys separated from their mothers. Science, 1967, 155, No. 3765. 1030-1031.

Rowell, T. E., \& Hinde, R. A. Vocal communication by the thesus monkeys (Macaca mulatta). Proc. Zool. Soc. London, 1962, 138, 279-294.

Seay, B. M., Hansen, E. W., \& Harlow, H. F. Mother-infant separation in monkeys. J. child Psychol. Psychiat., 1962, 3, 123-132.

Seay, B. M., \& Harlow, H. F. Maternal separation in the rhesus monkey. J. nerv. ment. Dis., 1965, 140, 434-441.

Van Hoof,, J. A. R. A. M. Facial expressions in higher primates. Sympos. Zool. Soc. London, 1962, No. 8, 97-125.

Yarrow, L. J. Separation from parents during early childhood. In M. L. Hoffman \& L. W. Hoffman (Eds.), Review of child development research. Vol. I. New York: Russell Sage Foundation, 1964. Pp. $89-136$.

\section{Notes}

1. This research was supported by National Institute of Health Grant (MH-11894), to Dr. Harry F. Harlow.

2. G. D. Mitchell is now at the National Center for Primate Biology, Davis, California; G. A. Griffin is an Assistant Professor of Psychology at the University of Waterloo, Waterloo, Canada; and G. W. Mbller's address is the Department of Behavior, the Zoological Garden, Copenhagen F, Denmark. 